\title{
De Kant a Fry: del formalismo trascendental al figurativo
}

From Kant to Fry: From Trascendental to Figurative Formalism

Paula Lizarraga Gutiérrez

Universidad de Navarra-España

Recibido: 10 de septiembre de 2014

Enviado a pares: 10 de septiembre de 2014

Aceptado por pares: 12 de noviembre de 2014

Aprobado: 19 de noviembre de 2014

Pensamiento y Cultura | ISSN: 0123-0999 | elSSN: 2027-5331

pensam.cult | Vol. 17-2 | Diciembre de 2014 | pp. 29-46

DOI: 10.5294/pecu.2014.17.2.2

$\diamond$ plizargu@unav.es 


\title{
De Kant a Fry: del formalismo trascendental al figurativo
}

Resumen: Este artículo pretende marcar una línea de continuidad entre algunos de los planteamientos de Kant en la Crítica del juicio y la teoría del arte de principios del siglo XX. El arte en este momento está cambiando, y las aproximaciones a las obras de los teóricos anteriores no resuelven plenamente los problemas que se están planteando los artistas. Es necesario, por tanto, buscar nuevas fórmulas que expliquen un arte de tendencia formalista y abstracta, las cuales se encontrarán -entre otras- en las teorías de la Einfühlung y la Sichtbarkeit, que toman algunos presupuestos kantianos -como las nociones de "juego de las facultades", "belleza libre" y "belleza adherente"- para explicar un formalismo que se aleja cada vez más del contenidismo idealista.

Palabras clave: formalismo, teoría del arte, Einfühlung (empatía), Sichtbarkeit (visibilidad), Roger Fry.

\section{From Kant to Fry: From Trascendental to Figurative Formalism}

\begin{abstract}
This article creates a line of continuity from the proposals in Kant's Critique of Judgement to the theory of art developed in the beginning of the twentieth century. Art creativity has exploded, art practice is changing so fast that theoretical thought is incapable of dealing with such a challenge. It is then peremptory to seek an explanation of the new formalistic and abstract trend in art found in the concepts of Einfühlung or Sichbarkeit, which take on some Kantian ideas such as "game of faculties", "free beauty" or even "adherent beauty", a starting point in showing a formalism which inevitably turns its back on idealism.
\end{abstract}

Keywords: formalism, art theory, Einfühlung (empathy), Sichbarkeit (visibility), Roger Fry.

Ya desde el siglo XVIII la idea de mimesis aplicada al arte es sustituida por la de expresión. Entender el arte como mimesis supone entender la actividad artística como copia, ya sea real o ideal, de la naturaleza. El término "expresión" significa "evocación de sentimientos" o "producción imaginaria de ideas". Se pasa, por tanto, de una consideración objetiva a una consideración subjetiva del arte. Ahora bien, la proclamación 
de la autonomía del arte que se estaba operando desde instancias teóricas y críticas, y desde la práctica artística misma, en el siglo XIX, no se detiene allí; al contrario, continúa y profundiza, en el siglo XX, en lo específico de la belleza artística y en la nueva disciplina estética. Todo este nuevo planteamiento se realiza a partir del desarrollo de algunos conceptos estéticos planteados por Kant en 1790 en la Crítica del juicio.

El sujeto trascendental kantiano es también un sujeto estético, ya que, como se afirmará más tarde, hay actitud estética en la medida en que se da una penetración de las cosas por nuestra personalidad. La psicología pasa así a formar parte fundamental de la concepción del arte y de la belleza como expresión. "Un movimiento de los órganos del cuerpo está vinculado constantemente con todos nuestros pensamientos" (Kant 1977, 54). De lo que podemos probablemente deducir que el efecto es recíproco. De la extensión de este principio es de donde extrae la teoría de la Einfühlung, el fundamento psicológico que aplica para esclarecer la experiencia estética, en un intento por conciliar los aspectos gnoseológicos y psicológicos de esta. La Einfühlung, o efusión simpática, permite explicar la percepción como un acto de difusión de nuestra vida interior en las cosas; como percepción simbólica, en virtud de la cual al conocer las cosas trasladamos a ellas nuestra subjetividad. Einfühlung es al mismo tiempo percepción y sentimiento, representación emocional y no simplemente asociación. Y así, como afirmara Volket —el representante más importante de esta teoría-, el arte es un acto de conocimiento simbólico. Mas en el arte esa síntesis es peculiar, ya que tiene lugar por medio de las sinestesias: como cuando un color produce directamente la evocación de una sensación táctil, acústica o térmica. Por tanto, a pesar de ser inmediatas, las percepciones artísticas son siempre sensaciones simbólicas, ilusorias.

En definitiva, se está hablando de la idea de un acuerdo del objeto con la constitución de nuestro ser, y esto recuerda el objeto estético de Kant, que está conformado a partir de la finalidad subjetiva del juicio reflexionante, del libre juego de nuestras facultades. Este supuesto de la proyección del sujeto sobre el objeto - que es la que provoca el sentimiento de placer que asociamos con el objeto- es el que intenta explicar la Einfühlung. 
Resulta curioso comprobar cómo algunos de los planteamientos más vitales del pensamiento estético de Kant aparecen para ser revisados solo a partir de la segunda mitad del siglo XIX, y lo hacen de la mano de dos doctrinas contrarias, en principio, a la especulación trascendental kantiana: la ya mencionada corriente psicológica de la Einfühlung y la corriente formalista de la Sichtbarkeit, o teoría de la visibilidad, que consiste en una vuelta al racionalismo y sus fundamentos realistas, liderada por Herbart y su escuela. Lo que hizo posible la combinación posterior de ambas teorías en modelos formalistas como el de Fry fue, precisamente, la común influencia kantiana.

Pero volvamos por un momento a la Crítica del juicio. Para entender lo que los visibilistas aportan al formalismo trascendental kantiano debemos decir, con Morpurgo (1971), que el mérito de Kant está más en la presentación de los elementos del proceso de la percepción que en su explicación y aplicación, de las que se ocuparán los teóricos de la visibilidad y los críticos formalistas. El análisis del juicio reflexionante nos lleva a la noción de "juego de las facultades" $\mathrm{y}$, en última instancia, a dos nociones fundamentales para estos posteriores desarrollos, pero que Kant simplemente apunta: la definición de imaginación estética como "esquematización sin concepto" y la distinción entre belleza libre y belleza adherente. A partir de esa definición y esta distinción, Herbart apela a una forma pura que en sí misma nada significa, consistente en un sistema de relaciones formales que unifican la multiplicidad de la apariencia sensible. A partir de aquí define el arte como la creación de un sistema de relaciones que otorga uniformidad a la realidad en la búsqueda de una forma pura. La belleza libre kantiana se transforma en belleza simple herbartiana, y esta última es la que se resuelve en una forma pura independiente de temas o motivos. Este planteamiento supone reducir todo conocimiento a la forma y toda belleza a la forma libre

1 La estética idealista, especialmente la hegeliana, reconoció tan solo la belleza adherente -son bellezas adherentes las de una mujer, un caballo o un edificio, las cuales presuponen un determinado objetivo que determina la función de aquella cosa y, por tanto, la idea de su perfección $-\mathrm{y}$ consideró la forma artística como manifestación sensible de la idea. 
de sentimiento. Con esto, Herbart oponía un formalismo abstracto al contenidismo de la estética idealista.

Lo que de aquí nos interesa es la aportación que este planteamiento supone para la crítica formalista. A la hora de las valoraciones artísticas, el juicio estético debe examinar en primer lugar la belleza simple que contiene la obra para poder aprehenderla en su integridad; solo posteriormente se podrán analizar los motivos concretos que esta presenta. El examen de esa belleza simple debe realizarse, según Herbart y sus discípulos, a través del análisis del sistema de relaciones formales - diferencia y semejanza, oposición y unificación, etc.- que constituye una obra de arte. Se entiende que este sistema de relaciones es medible, y así se establecen los fundamentos de la psicometría moderna, que se aplicó al estudio de las relaciones espaciales y permitió, posteriormente, investigaciones en psicología experimental que ayudaron a profundizar, por ejemplo, en el estudio de relaciones de consonancia y disonancia entre los colores o, en el dominio musical, entre los sonidos.

Las direcciones en las que se desarrolla la crítica formalista son muy variadas. El primer paso, ya apuntado, se centra en los fundamentos del formalismo desarrollados porla estética poskantiana en la Alemania del último tercio del siglo XIX. La obra de autores como Herbart, Fiedler, Zimmermann o Hildebrand articula, poco a poco, con la teoría de la pura visibilidad, el núcleo de arranque del formalismo. A partir de este punto se abre un abanico de posibilidades que abarca desde el formalismo más claramente antihistoricista del francés H. Focillon, pasando por la escuela italiana -B. Croce y L. Venturi, entre otros - hasta la combinación del análisis formal y filológico propuesta por Berenson y, por supuesto, la crítica formalista más directamente vinculada con el arte posimpresionista y practicada en Inglaterra por Roger Fry. La variedad es enorme, aunque abarcable gracias a los intereses comunes de sus protagonistas, todos los cuales se empeñan en relegar el posible contenido de la obra en favor de su forma y en orientar el estudio hacia el desarrollo interior del arte. 


\section{Idealismo crítico trascendental}

Kant (1724-1804)

La crítica del juicio<smiles>C1CCC1</smiles>

Idealismo romántico postkantiano

(Psicología $)+($ Gnoseología $)$

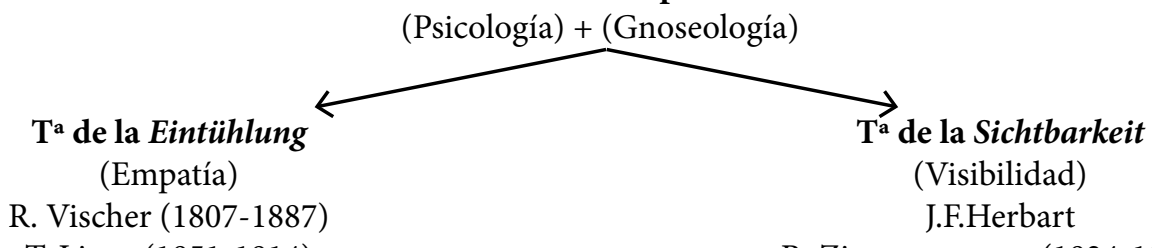

T. Lipps (1851-1914)

R. Zimmermann (1824-1898)

J. Volket (1848-1930)

K. Fiedler (1841-1895)

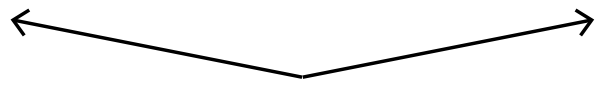

Modelos formalistas

A. Von Hildebrand (1847-1921

H. Wölfflin (1864-1945)

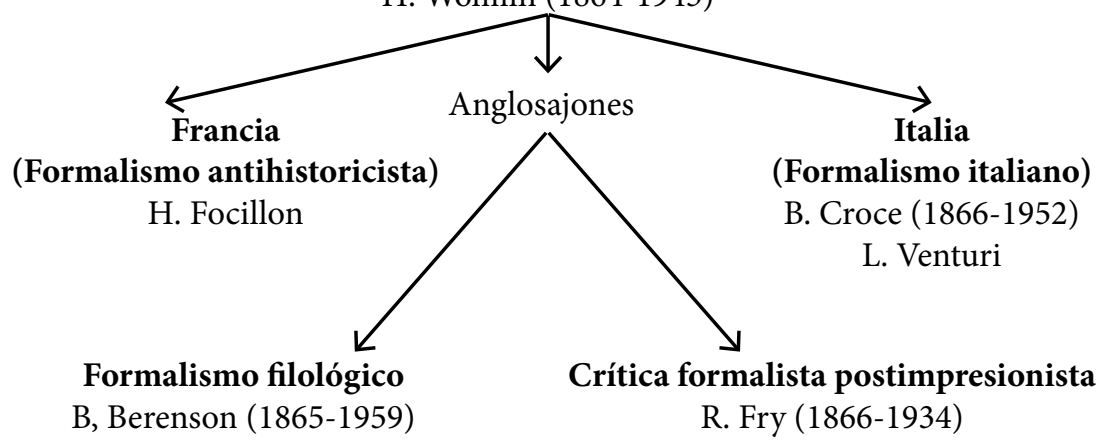

Konrad Fiedler (1841-1895) formula la teoría de la pura visibilidad siguiendo los pasos de Herbart y, por tanto, a partir de la revisión de ciertos principios kantianos. De Kant toma la existencia de formas a priori del conocimiento y la distinción entre una percepción objetiva y otra subjetiva. Según Fiedler, el arte se encuentra en el ámbito de la percepción objetiva y tiene sus formas a priori en la visión. Asimismo, ya no tiene sentido la distinción entre forma y contenido: se habla ahora de experiencia artística para referirse a la expresión de un nuevo aspecto de la realidad a través de la elaboración formal. Por tanto, el principio rector del arte será la creación de formas, las cuales se articulan gracias a las 
leyes ordenadoras de la visión del artista, porque solo ahí, según Fiedler, se conserva la aprehensión como apariencia perceptiva.

Una consecuencia directa de esta argumentación es la distinción entre teoría del arte y estética, o entre arte y belleza: el arte se ocupa de la representación de la forma, mientras que la belleza es un principio aplicable a los objetos naturales; la idea del arte se refiere exclusivamente a un proceso de configuración, cuyo objetivo no es necesariamente la concreción de lo bello. La relación entre una teoría del arte y una teoría de lo bello ha sido posible históricamente mientras se ha entendido la realidad como algo en sí, independiente de su relación con el sujeto. Pero Fiedler, heredero de Kant en este aspecto, no piensa así, y en su empeño por profundizar en la percepción artística, radicaliza sus planteamientos distinguiéndolos de las explicaciones psicológicas de la teoría de la Einfühlung. Si para esta, como hemos visto, toda representación implica una reacción orgánica coincidente con un hecho afectivo que introducimos en aquella, para Fiedler esta reacción orgánica, factor psicofísico del proceso de percepción, no se continúa en una emoción, sino en un gesto, en un movimiento figurativo, configurador: la visión artística es la percepción que acompaña a este impulso. La visibilidad de las imágenes artísticas es esta operación que da vida a sus formas: verlas es verlas producirse. Se sobreentiende que esta operación reproductiva no consiste en repetir la efectiva creación técnica, sino en un proceso creador ideal, intrínseco a la obra y espontáneo, en virtud del cual su forma se libera y se compone necesariamente como unidad. Se trata del estilo.

Tanto para el artista como para el espectador ya no se trata de prolongar en las cosas nuestros sentimientos personales, como afirmaba la Einfühlung, sino de adoptar una actitud activa, operante. Gozar del arte no es conocer el mundo exterior, sino crear un mundo más claro y riguroso. Las leyes que rigen este mundo son para Fiedler las de la visibilidad. Pero ¿qué leyes son estas? En definitiva, se trata de las formas espaciales de la óptica que Herbart desarrolló, a partir de las leyes de la estética trascendental de Kant, pero convertidas en relaciones geométricas en sentido estilístico: "En el mundo del arte las cosas se presentan al ojo como contenidas dentro de formas definidas, ordenadas, regulares" que constituyen "conexiones necesarias" (Fiedler 1958, 42). Comprobamos 
así que, en su empeño por distanciarse de la estética de lo bello, Fiedler vuelve sobre esta. No advierte que los términos "definido", "ordenado", "regular", no son otra cosa que medida, orden, número, considerados los principios de la belleza desde Platón y Aristóteles hasta la escuela de Herbart, pasando por la estética escolástica y la del Renacimiento.

En definitiva, Fiedler rescata las reglas de la sintaxis estética de los herbartianos y las aplica al arte figurativo, con lo cual sienta las bases para su posterior aplicación en el análisis y evolución de los estilos artísticos. Esos análisis estilísticos fueron desarrollados por sus discípulos: Hildebrand, Wölfflin o Riegl, y posteriormente aplicados al arte moderno por críticos como Bernard Berenson y Roger Fry.

Lo que me interesa ahora destacar de Adolf von Hildebrand (1847-1912), en este hilo - un tanto enmarañado- que nos conduce de Kant a Fry, es que, además de ser un gran teórico del formalismo, fue un importante escultor, y quizá la práctica artística le ayudó a forjar un auténtico modelo crítico. Además, es el autor que nos permite relacionar la teoría de la pura visibilidad, o Sichbarkeit, y la teoría de la Einfühlung. La unidad espacial de la representación artística es imaginaria y nada tiene que ver con la unidad orgánica de la naturaleza, pero a la vez está "en directa relación con nuestro sentimiento corporal” (Hildebrand 1988, 39) . Los valores plásticos y visuales son para Hildebrand el equivalente de los valores fisiológicos, de una sensación de la vida orgánica. Esta sensación se modula en volúmenes y superficies en el juego de los espacios y produce "un sentimiento infinito de la vida", una "impresión de autentico enriquecimiento" (Hildebrand 1988, 30), una vitalidad mayor. Este efecto fisiológico atribuido a la representación artística no resulta nuevo. Hildebrand lo toma de los autores de la Einfühlung.

En su obra fundamental, El problema de la forma en la obra de arte, aparecida en 1893, la investigación de Hildebrand parte de la identificación entre forma y visión, y define el arte por su sujeción constante a las leyes de la forma. Distingue, además, dos tipos de visión: la cercana, o táctil, y la lejana, u óptica. La visión cercana es de naturaleza analítica y se compone de la acumulación de impresiones sucesivas mediante el movimiento ocular constante. Por el contrario, la visión lejana es de naturaleza sintética, unitaria y simultánea. Esta última es la visión del artista, 
el fundamento del conocimiento artístico, y es una visión unificadora, de índole superior. Para Hildebrand, a diferencia de lo planteado por sus antecesores, el carácter unitario de la visión artística ya no procede de una adecuación ideal entre las partes, sino de la mirada del propio artista.

Esta doble forma de visión la traslada Hildebrand a la realidad formal. Habla, por tanto, de formas reales y formas aparentes. Las primeras son las formas propias de las cosas, la forma de la existencia. La forma aparente, por su parte, es el modo como se muestra la realidad, la forma del efecto que esta produce en nosotros y que "está compuesto por el producto común del objeto, por una parte, de la iluminación, del entorno y del punto de vista cambiante, por otra" (Hildebrand 1989, 33). Las formas aparentes, dirá, despiertan en el espectador sensaciones de espacio y movimiento, y también sentimientos, que dan lugar a la creación artística.

Las dos tesis fundamentales de Hildebrand, la vinculación de la unidad de la visión artística con una mirada subjetiva y la afirmación de que la forma en que se muestra la realidad no provoca solo impresiones visuales sino también sentimientos, nos permiten relacionar la teoría de la pura visibilidad y la teoría de la Einfühlung. Vemos en Hildebrand la idea de una relación entre naturaleza y subjetividad mediada por la forma, ya que aunque este afirma que la unidad de la visión del arte y la unidad orgánica de la naturaleza son distintas, se establece entra ambas una especie de acuerdo. Tanto para las teorías visibilistas como para la teoría de la proyección sentimental el arte se entiende en términos de creación de una percepción de lo real gracias al paralelismo entre la naturaleza y aquel; una proximidad que no radica en la identidad de apariencia, sino en la facultad de suscitar una representación espacial común. El arte, y este es su valor intrínseco, enriquece nuestra relación con la realidad al deducir, por talento e imaginación del artista, sus leyes estructurales esenciales hasta "liberarla para nosotros del cambio y del azar" (Hildebrand 1989, 41). Esto es lo que convierte a la representación artística en un modo de conocimiento y le otorga una función moral, además de que preserva su autonomía al liberarla de la simple reproducción. Y así, la forma artística, aunque deducida de la forma real, es una plena creación, es de hecho una elaboración unificadora de la realidad. 
Con Hildebrand se formula la teoría de la visibilidad como una teoría de la expresión que está dispuesta a descubrir las transformaciones estilísticas aparecidas a lo largo de la historia de la visión artística. Esta tarea será llevada a cabo por H. Wölfflin (1864-1945), autor de sobra conocido, sobre todo por su obra Conceptos fundamentales en la historia del arte, publicada en 1915, en la que insiste en una visión configuradora basada en la idea de que las distintas maneras de representar están en relación con distintas maneras de ver. Asimismo, Wölfflin formula sistemáticamente las leyes del estilo y los principios mediante los cuales la forma cambia o evoluciona a partir de determinadas categorías formales articuladas como pares de conceptos opuestos que explicarían el paso del estilo renacentista al barroco. Lo inspira especialmente un interés histórico: el de aprender, a través de la evolución de los estilos, el pasaje de unas épocas a otras, entendido como un cambio de sentimiento fundamental o disposición espiritual de cada época. Así, habla de pasar de la tendencia lineal al gusto pictórico, de las visiones superficiales a las profundas, de las formas cerradas a las abiertas, de una representación múltiple, rítmica, a una unificación total, de la claridad a la indeterminación. La polarización de esas dos formas estilísticas se convierte sin más en el fundamento de la historia del arte. Esta tesis tiene un valor relativizante: no existen estilos mejores que otros, existen simplemente estilos distintos como existen miradas diferentes. El barroco no es una decadencia del clasicismo, como dirían quienes siguen un esquema evolucionista nacimiento-florecimiento-decadencia, sino otra manera de representar. Los juicios de valor solo pueden emitirse dentro de los límites de cada configuración óptica o estilo. Wölfflin es quizá el teórico más importante del formalismo. Sus reflexiones recogen el pensamiento de iniciadores de esta corriente, como Adolf von Hildebrand o Konrad Fiedler. El título formalista se le aplica a veces con sentido descriptivo y a veces con intención crítica. El propio Wölfflin afirma al respecto:

Se me considera el "formalista" entre los historiadores del arte. Acepto el título como un título de honor, si es que significa que siempre he considerado que la primera tarea del historiador del arte es el análisis de la forma visible (Wölfflin 1988, 11). 
En el arte hay una evolución interna de la forma. Por meritorios que sean los esfuerzos para relacionar el continuo cambio de formas con las condiciones cambiantes del entorno, y por indispensables que sean el carácter humano de un artista y la estructura social y espiritual de una época para explicar la fisonomía de la obra de arte, no hay que ignorar que el arte, o para decirlo mejor, la imaginación creadora de formas, tiene, según sus posibilidades más generales, una vida y una evolución que le son propias (Wölfflin 1988,15).

A pesar de que en este párrafo Wölfflin afirma que el objetivo de la historia del arte es el análisis de la forma, se defiende de la acusación según la cual su formalismo no tiene en consideración elementos de contenido:

Pero el término de formalista contiene también el reproche de haber considerado el análisis de la forma visible como tarea primera y final, desdeñando así el sentido y el espíritu del arte. Ahora bien, la palabra "forma" tiene significados muy diversos, pues al fin y al cabo todo es forma en las artes plásticas, y un análisis formal completo captará necesariamente el elemento espiritual (Wölfflin 1988, 11).

Para Wölfflin la capacidad de ver evoluciona casi por sí sola de lo lineal a lo pictórico "hasta el punto de que uno se pregunta si no se trata en realidad de una evolución puramente interna" (1985, 355). Estos conceptos, por otro lado, son irreversibles; es decir, la evolución para Wölfflin se da siempre en un sentido, de lo lineal a lo pictórico, puesto que lleva en sí una idea de progreso. Para este autor,

su sucesión no puede invertirse. Una ordenación disimulada solo puede aparecer después de una ordenación evidente, lo parcial y lo oscuro solo pueden admitirse como principio de la imagen a partir de una precedente claridad absoluta, la captación plástica del mundo de los cuerpos es necesariamente anterior a la aprehensión de la imagen pictórica en su conjunto, de la apariencia pictórica, del movimiento pictórico, de la luz, etc. (Wölfflin 1988, 33). 
El sistema presente en los Conceptos fundamentales ha sido bastante criticado. En primer lugar, se ha señalado que la universalización de sus pares polares proponía una reducción de la historia del arte a una fase clásica y otra barroca en todas las épocas. Otra de las críticas es que no necesariamente todas las manifestaciones barrocas participan de los conceptos otorgados a este estilo. Así, la vertiente clasicista del barroco no encaja tan perfectamente en su esquema. Por otra parte, la evolución necesaria de lo clásico a lo barroco, o de lo lineal a lo pictórico, tampoco es comprobable en la historia del arte. Esta univocidad está basada en una idea de progreso de la historia, lo cual significa una contradicción con sus tesis relativistas, cuya importancia fundamental ya hemos destacado. También puede comprobarse que algunas obras pertenecen en parte a lo lineal y en parte a lo pictórico. Todo esto debe llevarnos a una matización que, sin aceptar el sistema wölffliniano con rigidez y en su totalidad, permita utilizar algunos de sus conceptos de mayor claridad interpretativa. Después de todo, estas categorías han contribuido a articular el análisis estilístico de la obra de arte, y después de Wölfflin no hay prácticamente ningún crítico formalista que no se haya servido de ellas de alguna manera. Además, debemos reconocer la gran aportación que supone ese sistema: enseñarnos a ver y reconocer que la visión tiene una historia.

Por último vemos que la concepción de Wölfflin superpone dos niveles de orden diferente. Por un lado, el nivel fundamental para el historiador del arte, el formal, en el cual se registra una evolución de la forma que está sujeta a ciertas leyes, que es universal y general; es el ámbito del estilo. Por otro lado, el nivel del significado, ya que el cambio de formas siempre se corresponde con un cambio de mentalidad y sensibilidad entre épocas. Tales niveles no son mutuamente excluyentes, sino que conviven y se expresan en la "forma" en sentido amplio, puesto que para Wölfflin en las artes plásticas no hay expresión posible si no es a través de la forma.

Después de esta rápida y somera revisión de las teorías estéticas formalistas, llegamos por fin al modelo de Roger Fry, no sin antes apuntar que su influencia más inmediata es la del crítico y atribucionista Bernard Berenson, nacido un año antes que Fry y que, además de amigo - mantuvieron cierta correspondencia-, fue quien lo guió en el conocimiento de los pintores italianos del Renacimiento. 
Al definir las pautas del análisis formal, Berenson atribuye el valor del arte - o de la experiencia estética- a su capacidad de conmover, de suscitar en el espectador sensaciones fisiológicas y efectos sentimentales. Por ello, dicho autor define el arte como un medio para intensificar la vida. Ahora bien, el arte es expresión viva susceptible de conmover o vivificar gracias a su carácter formal. Solo mediante la forma estimula la conciencia y el cuerpo del espectador, y únicamente en la forma reside el valor comunicativo y la significación del arte. Los medios formales con los que cuenta la obra de arte para intensificar la vida son, fundamentalmente, los valores táctiles y el movimiento, y en un segundo término, la proporción, la disposición y el color. Hay que destacar, por último, la unión llevada a cabo por Berenson del formalismo y la técnica atribucionista. Fue en su obra Los pintores italianos del Renacimiento (1897) donde los test morellianos, previamente clasificados, se unen a las categorías formalistas (valor táctil, movimiento, composición espacial) para fundamentar constantes estilísticas y tesis de atribución.

Una de las acusaciones tradicionalmente dirigida a Berenson se refiere a su gusto casi exclusivo por el arte del Renacimiento, sin conseguir dar al formalismo fundamento para la crítica del arte moderno. Este paso fundamental se produce con el modelo crítico de Roger Fry. Efectivamente, la descripción de la pintura florentina realizada por Berenson fue lo que despertó en Fry la necesidad de desarrollar un análisis formal que pudiera actuar de patrón para la comprensión crítica del arte moderno.

Y este es quizá el gran logro de Fry: conseguir que los fundamentos de la mejor tradición de la estética formalista sirvan para entender y valorar con criterios más objetivos el arte moderno y contemporáneo. Con ello nos demuestra no solo la necesidad de que la teoría del arte adecúe sus conclusiones a las transformaciones de la historia del arte, sino también la importancia de estas transformaciones para la confección de modelos teóricos.

Fry plantea una teoría formalista en la que divide la actividad intelectual en dos aspectos: instintivo e imaginativo. La actividad instintiva está regida por el espíritu práctico, de modo que elabora una captación del mundo mediante el análisis y la formulación de conceptos. La vida imaginativa, en contraste, es contemplativa y sintetizadora, ajena al 
mundo práctico y a los problemas morales. Mientras que la vida instintiva se expresa por medio de la acción y la conducta, la vida imaginativa lo hace por el arte. No cabe duda de que detrás de este dualismo se esconde la distinción propuesta por Hildebrand entre visión táctil y visión óptica. Pero Fry va mas allá, ya que para el arte plantea una doble visión. Así lo propone en La visión del artista (1988), donde diferencia la visión estética y la visión creativa como dos modos distintos de asimilación del mundo desde la vida imaginativa. La visión estética es la simple aprehensión formal de la realidad, lo cual le quita toda utilidad por el hecho de ser previa a la conceptualización de esta última. La pasividad de la visión estética se torna actividad en la visión creativa, que reelabora la apariencia de la realidad registrada en la visión estética y es una característica exclusiva del artista. De acuerdo a este planteamiento podemos deducir que la aprehensión formal de la realidad (la visión estética) es un paso previo tanto para la actividad analítica (instintiva) como para la artística (imaginativa).

Con estas y otras ideas se adhiere Fry al formalismo. Considera que el rasgo fundamental del arte es la creación formal de una imagen resultado de una percepción en la cual no se produce acción frente al estímulo exterior, de modo que en ese sentido es distinta a la que domina en la vida real. Así, encontramos en Fry una fuerte defensa de la plena autonomía del arte en tanto que los acontecimientos exteriores no tienen competencia sobre la visión creativa. Ahora bien, la creación artística acoge para el crítico inglés un valor emocional. Una emoción presente en la forma en sí misma, en su sistema de relaciones entre los distintos valores formales capaces de producir un efecto sobre el espectador. Así lo explica Fry: "A pesar de que poca gente sea consciente de ello, las cualidades formales influyen en su reacción ante una pintura, aunque pasen, casi inmediatamente, de ellas a otras consideraciones" $(1988,172)$. Los elementos artísticos se transforman en emociones por medio de la fisiología; es decir, el artista provoca reacciones físicas a través de impresiones en la retina.

Por todo lo dicho hasta aquí, creo acercarme a la realidad al afirmar que en la crítica de Fry se mezclan una metodología empirista y otra criticista —en el sentido del criticismo kantiano, se entiende-. De esta 
confluencia habla implícitamente todo el magnífico ensayo sobre Paul Cézanne que publica en 1927. Intentaré, a modo de esbozo, destacar algunos de los aspectos de esta crítica que - aunque ya mencionados la mayoría en este ensayo- me parecen más relevantes y significativos.

En la vida de Fry se advierte una inicial desconfianza hacia el arte de sus contemporáneos y un interés por los elementos compositivos de la pintura que, influido por Berenson, lo llevan al estudio de los pintores primitivos italianos.

Este descubrimiento de los elementos compositivos, en clara relación con las tendencias formalistas del momento, le va a permitir en último término una comprensión de la pintura moderna mucho más lúcida que la del resto de la crítica de su tiempo.

Este talante experimental lo aleja de cualquier noción a priori de lo que sea la esencia del arte y de la belleza, a los que llega no a través de preocupaciones teóricas, sino atraído por las indagaciones sobre la naturaleza de la percepción y de la expresión formal de las emociones. Esto explica que las nociones que aparecen en la crítica de Fry tengan un carácter heurístico y operativo.

Para Roger Fry el trabajo crítico conlleva la búsqueda de la lógica interna del modo de proceder artístico, lo que supone una identificación entre la visión del artista y la del crítico o espectador. De ahí que en su crítica pase sin solución de continuidad del punto de vista del creador al punto de vista del receptor. En otras palabras, la teoría de la percepción en la crítica de Fry es una teoría de la recreación, con lo cual se adhiere a los planteamientos formalistas de Hildebrand y Berenson.

La creación artística es para Fry un proceso de conformación de relaciones formales significativas. El arte es el ámbito de la inteligibilidad de las emociones, y esta inteligibilidad comparece en las nociones centrales de la crítica de Fry, que son las de sensibilidad, vitalidad y plasticidad.

La sensibilidad se refiere a los cambios o variaciones expresados plásticamente, aunque implica la existencia de un principio constante que subyace a las variaciones y que sirve como elemento conductor de estas. Es importante notar que ambos aspectos son inseparables, ya que no pueden entenderse desligados de la materia o textura con la que trabaja el artista (unidad en la variedad/desaparición del dualismo contenido-forma). Este 
modo de concebir la sensibilidad se decanta en una concepción orgánica del arte a la que responde la noción de "vitalidad".

De ninguna de estas nociones cabe una definición, pero menos aún de la de vitalidad, porque en esta se juega la singularidad expresiva de lo artístico. No se trata de un concepto definido, cerrado, sino de un concepto operativo que Fry ensaya en su aproximación a las obras de arte. Esta vitalidad se refiere a la vida interior de la obra misma, a la energía vital expresada en la totalidad de los elementos formales. Prácticamente todos los formalistas han planteado, de una u otra manera, esta idea de la vitalidad en la expresión artística: Kant, cuando habla del libre juego de las facultades y del gozo o la intensificación vital; Herbart habla del arte como sistema de relaciones formales que unifica la multiplicidad y vivifica la realidad; Fiedler habla de la experiencia artística como esa visibilidad que da vida a las formas; Hildebrand menciona esa vitalidad cuando alude a la capacidad del artista de enriquecer y vitalizar nuestra relación con la realidad por medio de unas leyes estructurales, que de alguna manera eternizan esa realidad... En definitiva, la satisfacción estética depende de esa energía vital percibida en los elementos plásticos que configuran la representación.

Por último, la plasticidad está constituida por una serie de conceptos formales entre los cuales cabe destacar, en primer lugar, la línea, que Fry concibe como trazo o gesto y en la cual son fundamentales los elementos rítmicos. En segundo lugar, la masa, indisociable del espacio, que constituye el elemento de resistencia o inercia sin el cual el movimiento o dinamismo sería inexistente. Y, por último, la luz, la sombra y el color, que expresan la dimensión emocional y que están presentes en los elementos plásticos anteriormente aludidos.

Ninguna de estas nociones - línea, masa, espacio, luz, sombra y color-, que aparecen recurrentemente en la crítica de Fry, abandona nunca el punto de partida: su indisociabilidad de la emoción artística originaria. Esto es lo que le permite a Fry hablar del significado del arte en términos no solo estéticos, históricos, críticos, etc., sino como una expresión específicamente humana. Por ello la realidad artística reclama su comprensión y su valoración en el ámbito también específicamente humano del receptor. 
El crítico o el historiador del arte deben afrontar el difícil tema de las valoraciones artísticas. La valoración del arte depende del empeño por penetrar en su universo propio. La atención a la realidad plástica de la obra supone una sensibilidad despierta, que burla prejuicios y predilecciones innatos para abrirse a la recepción de aquella.

La valoración de lo artístico nace del análisis del lenguaje plástico mismo, que de este modo se vuelve elocuente. Fry no busca el aislamiento de la supuesta objetividad de lo artístico, entre otras cosas porque advierte que el arte es un asunto entre seres humanos. Este modo de entender el arte explica la atención de Fry a la biografía de los artistas. Su obra sobre Cézanne es, en este sentido, paradigmática: ateniéndose estrictamente a la evolución del lenguaje pictórico del artista aparece un retrato magistral de la personalidad de Cézanne. La virtualidad de la crítica de Fry se pone de relieve en su capacidad de hacer presente la pintura de Cézanne con sus palabras. En ese esfuerzo se encuentra su logro fundamental. El lenguaje - literario- se funde de tal modo con el ritmo de la plástica de Cézanne que cabe concluir que su Cézanne es una cumbre desde el punto de vista crítico.

Sin embargo, a pesar de esa penetración en la plástica - mediante un estudio pormenorizado, analítico y completo como el que realiza Fry- y de la aproximación teórica al proceso de creación artística, Fry no da una explicación acabada de la pintura de Cézanne. Lo que ocurre al término de su trabajo es que la realidad artística no queda disecada por sus análisis, sino vivificada, pues permite siempre volver sobre sus interpretaciones sin agotar nunca la realidad misma que entrañan, simplemente esperando que nos revele su misterio. Su análisis de las obras de arte, no le revelará la verdad última de la belleza de estas. El esfuerzo no implica la revelación. Sin embargo, se dedicará a ello de por vida, y las respuestas llegarán, pero indirectamente, muchas veces donde no las buscaba. 


\section{Bibliografía}

Fiedler, Konrad. 1958. De la esencia del arte, selección de sus escritos realizada por Hans Eckstein. Buenos Aires: Nueva Visión.

Fry, Roger. 1988. "La visión del artista" en Visión y diseño. Barcelona: Paidós.

Hildebrand, Adolf von. 1989. El problema de la forma en la obra de arte. Madrid: Visor.

Kant, Immanuel. 1977. Crítica del juicio. Madrid: Espasa-Calpe.

Morpurgo Tagliabue, Guido. 1971. La estética contemporánea. Buenos Aires: Losada.

Wölfflin, Heinrich. 1985. Conceptos fundamentales de la historia del arte. Madrid: Espasa-Calpe.

Wölfflin, Heinrich. 1988. Reflexiones sobre la historia del arte. Barcelona: Península. 